\title{
Un vistazo diferente a la Responsabilidad Social Empresarial'
}

\author{
Carolina Quinteros \\ Departamento de Economía \\ UCA, San Salvador
}

RESUMEN: La Responsabilidad Social Empresarial es un con-

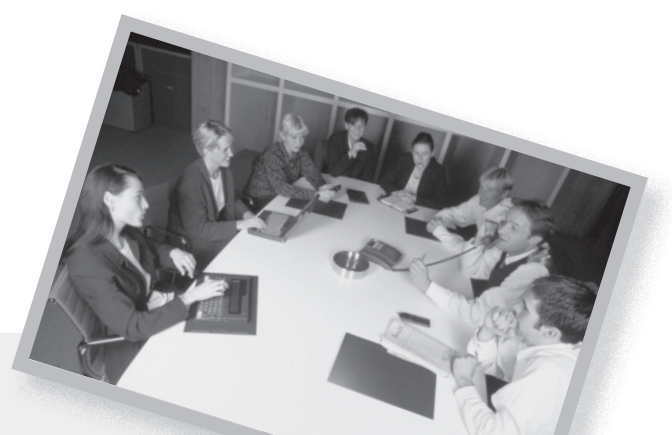
cepto que ha tomado auge en los últimos años. Erróneamente identificado con la filantropía, este concepto ayuda a establecer deberes para las empresas, tanto hacia la sociedad en la que se desempeñan como hacia el personal con el que trabajan. La autora revisa la importancia de la Responsabilidad Social Empresarial dentro del mundo de los negocios y el de la lucha por los derechos humanos. Una pregunta clave que se formula en estas páginas es hasta qué punto se puede emplear este concepto para que el sector privado mejore las condiciones laborales.

ABSTRACT: Social Corporate Responsibility is a concept currently in vogue. Misidentified with philanthropy, Social Corporate Responsibility establishes that corporations have social and labour duties to accomplish. The author reviews the importance of Social Corporate Responsibility inside the corporate world and in the struggle for human rights. A key question posed in this essay is until which extent Social Corporate Responsibility can help to improve labour conditions. 
La Responsabilidad Social Empresarial (RSE) aporta novedades para el establecimiento de deberes del sector privado con la sociedad en la que hace negocios, en el ejercicio de rendición de cuentas de las empresas - especialmente las transnacionales- y en la reducción "voluntaria" de las externalidades causadas por la actividad productiva. Es un tema novedoso y un paso importante en establecimiento de nuevas reglas para la actividad económica en la era globalizada. En estos tiempos en que el mercado paulatinamente (a veces vertiginosamente) desplaza al Estado en muchas de sus funciones, esta es una discusión en la que vale la pena participar.

El artículo se divide en cuatro partes. La primera nos presenta la relevancia del tema en las agendas de negocios y activistas de derechos humanos. La segunda, es una revisión del concepto de RSE y de su potencial; así como de otros conceptos relacionados con prácticas comerciales alternativas o con el interés de hacer que el mercado ofrezca herramientas para el mejoramiento de las condiciones de trabajo. La tercera, nos intenta comunicar por qué la RSE es un tema relevante para las empresas y las marcas. Finalmente, nos planteamos la pregunta sobre la potencialidad de usar a la RSE como herramienta para la denuncia y la demanda de las organizaciones y actores interesados en que el sector privado asuma mayor responsabilidad en el mejoramiento de las condiciones de trabajo y de vida de sus trabajadores y trabajadoras.

\section{Un tema de moda}

La Responsabilidad Social Empresarial se ha vuelto atractiva. Casi cada investigación sobre este tema nos dice que cada vez es más importante en la forma de hacer negocios a nivel global. Uno de los más elocuentes estudios es el realizado por la Corporación de Finanzas Internacionales del Banco Mundial (WBG/IFC, 2003) con base en encuestas a representantes de más de 107 empresas transnacionales de capital estadounidense, canadiense y europeo; que se encuentran trabajando en los sectores de agroindustria, manufactura e indus- trias extractivas. Las entrevistadas son empresas con liderazgo en el mercado global, con altas ganancias que en promedio, ascienden a 15.5 millones de millones de USD, anualmente.

Este estudio sostiene que:

- El $80 \%$ de las empresas encuestadas dice que toman en cuenta el desempeño en materia de RSE de sus potenciales socios antes de cerrar un trato, ya sea mientras analizan socios potenciales o ubicaciones $(55.1 \%)$ o antes de cerrar el negocio (27.1\%). 
- El 61\% expresa que los temas de RSE son al menos tan importantes como los asuntos tradicionales de negocios (precios, calidad, etc.) a considerar al momento de establecer relaciones con socios nuevos.

- El $88 \%$ de las empresas encuestadas manifiesta que los factores relacionados con la RSE tienen influencia para determinar el lugar o país donde van a invertir y el proveedor que van a seleccionar.

- Al menos el $52 \%$ de estas empresas dice haber optado por un socio, país o proveedor, tomando en cuenta criterios de RSE. En el sector de manufactura, el 58\% expresó que este criterio no sólo los había hecho escoger un socio, sino también cortar relaciones con otros que mantenían un deficiente desempeño en RSE.

- Casi el 60\% de las empresas dedicadas a la manufactura terminó relaciones con un socio por faltas en RSE. En este sector, al menos el $40 \%$ de los consultados dijo que este mismo problema los habían Ilevado incluso a salir de un país.

- La falta de un gobierno fuerte en la regulación del accionar de las empresas, en lugar de ser una ventaja (como algunas empresas salvadoreñas podrían pensar), es considerada por las empresas como una deficiencia que las hace desistir de invertir en un país. El $66 \%$ de estos encuestados dice que, al contrario de la creencia popular, las reglas del juego claras, regulaciones fuertes y leyes que se cumplan son un incentivo para invertir en un país.

- Los asuntos de RSE más importantes para estas firmas son los ambientales y laborales. En manufactura, los asuntos relacionados con derechos laborales ocupan el $80 \%$ del tiempo de trabajo del personal interno de RSE y es por tanto, prioritario en su agenda.

Otros estudios sostienen que el público consumidor en los principales mercados de EE.UU. y la UE, cada vez se interesa más seriamente en el consumo políticamente correcto y está dispuesto, incluso, a pagar un poco más por un bien que haya sido elaborado con respeto a los derechos las personas que lo trabajaron.

Uno de estos estudios (Elliot y Freeman, 2000), expresa que hay suficiente evidencia para sustentar tal afirmación y citan varias encuestas. En una de ellas se conoce que muchos consumidores pagarían un poco más por un bien elaborado bajo condiciones de trabajo apropiadas. En promedio, los entrevistados dijeron que podrían pagar hasta un $28 \%$ más del valor de un producto de 10 USD y un $15 \%$ de uno de 100 USD. Cerca de dos tercios de los encuestados manifestaron que bajo ninguna circunstancia comprarían una camiseta hecha en pobres condiciones laborales o ambientales y el tercio restante dijo que sí lo haría, pero sólo si le otorgan un descuento. 
Analizando los resultados e incorporándole un análisis de elasticidad de oferta y demanda, el estudio concluye que las empresas pueden perder dinero si sus productos están identificados como hechos en malas condiciones. Sin embargo, también se reconoce que no hay mucho margen para elevar los precios de los bienes que se han hecho con mejores prácticas, a menos que los productos de la competencia sí tengan mala reputación. El público consumidor promedio, según este estudio, sí responde a la información que se disemina sobre el desempe- ño de las compañías en materia de responsabilidad empresarial y, aunque no necesariamente premia de manera inmediata a las empresas con buen desempeño, sí castiga a las compañías con antecedentes de deficiente manejo de RSE.

Centroamérica se encuentra en pleno ejercicio de apertura al exterior, de búsqueda de inversión extranjera directa y de inserción en la globalización. En este ambiente, ¿Tiene alguna utilidad plantearse la RSE como herramienta para mejorar las condiciones de trabajo y de vida de la población centroamericana?

\section{Enfoques y conceptos de RSE}

Responsabilidad social significa muchas cosas. Significa que una empresa debe conocer a su cadena de proveedores y ayudarlos a que incorporen mejores prácticas. Significa productos responsables que no afecten la salud de la población. Y también la aplicación de métodos de fabricación responsable, que contemplen las innovaciones si causar daño al medio ambiente. Significa relaciones laborales responsables que maximicen la productividad y mejoren las condiciones de trabajo, y relaciones responsables con la comunidad donde la empresa invierte, para el mejoramiento de las condiciones de vida de los miembros de esa comunidad.

Stephan Schmidheiny, en una ponencia presentada en el Congreso ConvertiRSE. Cuidad de Guatemala, 3 y 4 de marzo, 2004.

\section{a) La evolución del concepto}

El concepto de RSE es un tema novedoso y sugerente. Hace pensar en empresas que se preocupan de hacer negocios con ética, sin provocar externalidades y con respeto a su personal. Cuando el concepto se aplica a las empresas transnacionales se nos presenta una imagen optimista de la globalización: es posible encontrar un balance entre la búsqueda de ganancias y el compromiso con los de- 
rechos humanos y ambientales y con prácticas comerciales justas.

Sin embargo, aún hay mucha confusión sobre lo que es y lo que no es RSE. Muchos piensan la RSE como acciones aisladas o continuas de filantropía, por ejemplo, donaciones más o menos importantes a escuelas, hospitales, equipos deportivos, etc. En estos casos, la RSE es vista como una acción de la empresa hacia fuera y no como una práctica ligada a la vida cotidiana e interna de la misma, quitándole el potencial transformador que podría tener y dando espacio a las sospechas de quienes argumentan que todo el asunto es apenas un ejercicio de relaciones públicas.

Otras opiniones, centran el estudio de la RSE como una política de la empresa para causar externalidades o no hacer daño, ya sea al medio ambiente o a la población trabajadoras y la comunidad involucrada; pero aún así, sigue siendo un concepto restringido y vago. Entre otras cosas, porque no siempre se tiene claridad y hay consenso sobre lo que se considera dañino. Por ejemplo, hasta hace pocos años, el fumar no era considerado perjudicial y las compañías tabacaleras no hacían público los efectos del cigarrillo en el ser humano. Más bien el cigarrillo era socialmente aceptado como símbolo de estatus, elegancia, sex appeal y hombría, para mujeres y hombres, respectivamente. "Fumar es un placer genial, sensual", nos decía Sarita Montiel, interpretando un viejo tango español.

Afortunadamente, hay un creciente interés en ver la Responsabilidad Social de manera proactiva, más amplia y vinculada en primer lugar al cumplimiento de la legalidad. La legalidad sería entendida como las leyes nacionales, pero también otros dictámenes de foros internacionales tales como las reglas emanadas de la OMC, los convenios de la OIT, acuerdos internacionales de protección al medio ambiente y convenciones internacionales en materia de derechos humanos.

Los conceptos sobre RSE expresados por los mismos empresarios (como Stephan Schmidheiny, uno de sus principales promotores a nivel mundial), instituciones académicas (como el INCAE) y agencias de cooperación (como el BID y el Banco Mundial), no dejan lugar a equívocos sobre la amplitud del concepto.

El mismo Stephan Schmidheiny sostiene que:

El concepto básico de responsabilidad social empresarial (RSE) se funda en el respeto por la ley. En los países de América Central se necesita continuar poniendo énfasis en este punto, ya que cuando una empresa no se mueve dentro del marco establecido por la ley, ninguna de sus acciones, ni siquiera aquellas vinculadas con la filantropía en el sentido tradicional, resultan sostenibles. El respeto por la ley se verifica en el cumplimiento de compromisos de carácter nacional -expresados por le- 
yes nacionales existentes, aunque muchas veces ignoradas $-y$ compromisos internacionales, regulados por organismos como la Organización Mundial del Comercio (OMC), la Organización Internacional del Trabajo (OIT) y la Organización Mundial de la Salud (OMS), entre otros.

En este contexto, nos corresponde a las empresas de la región ser actores transparentes, proactivos, en la tarea de erradicar, no sólo la práctica de evadir las leyes y la imagen de la facilidad con que es posible hacerlo, sino también la falsa creencia de que la evasión es sinónimo de competitividad. Le corresponde, en consecuencia, al empresario centroamericano la tarea de "convertirse" en el arquitecto de una región altamente competitiva que, inserta en un mundo globalizado, le garantice a sus 35 millones de habitantes un desarrollo integral y sostenible (Schmidheiny, 2004).

En este sentido, las prácticas de filantropía de empresas que evaden impuestos, contaminan el ambiente, no dan información completa y verdadera de su producto a sus consumidores o no respetan los derechos de sus trabajadores y trabajadoras, no entran en la clasificación de socialmente responsables, aunque así lo diga su propaganda. Pese a la relevancia de la legalidad, este es apenas el primer paso. El respeto a leyes y regulaciones es condición necesaria pero no suficiente para caracterizar a una empresa como socialmente responsable.

La RSE implica hacer bien las cosas más allá de lo que es legalmente requerido y actuar conforme a un código de conducta ético incluso en aquellas ocasiones en las que la ley permite a las empresas evadir sus obligaciones. Esta afirmación es especialmente útil en sociedades en las cuales las leyes no son suficientemente fuertes, donde es relativamente fácil evadirla o, como sucede muchas veces en países altamente dependientes de las inversiones extranjeras, el mismo Estado prevé mecanismos para que se interprete de manera laxa sus propias regulaciones (Bull, 2003).

Autores como Bull sostienen que la RSE implica un ámbito de acción en al menos tres áreas, correspondientes a tres principales de los negocios que deben ser tomados en cuenta:

a) El primero es la ganancia. Una empresa debe producir beneficios, pero éstos no deben ser considerados solamente como la generación de ingresos para los dueños y accionistas sino, además, la generación de bienes sociales tales como empleos adecuadamente remunerados para sus trabajadores y trabajadoras. 
b) El segundo es el impacto en el medio ambiente. Debe vigilarse que la actividad empresarial no ocasione daños ni afecte los recursos naturales.

c) Finalmente, las empresas deben ocuparse del impacto social de sus actividades. Esto implica poner atención a los efectos que la actividad de la empresa tiene para las personas, comenzado con sus propios empleados, pero no limitándose a ellos, sino también vigilando el impacto en la comunidad en que se desenvuelve y la sociedad en su conjunto. Las empresas socialmente responsables deben procurar un ambiente de trabajo seguro $y$ buenas condiciones de empleo y de vida para sus trabajadores $y$, al mismo tiempo, prestar atención a temas tales como derechos humanos, condiciones de trabajo en sus compañías socias y suplidoras, contribuciones a la comunidad, etc.

La RSE, además, no es un tema que le compete sólo a las empresas. Un manejo adecuado de estas políticas requiere de una acción conjunta entre diversos actores interesados, más allá de los inversionistas. Estos actores son en primer lugar los empleados, los clientes y la comunidad local, pero no se excluye a otras organizaciones sociales, activistas que hayan mostrado interés en la conducta de la compañía y por supuesto, el Estado.

Adicionalmente, la compañía socialmente responsable, tiene que ser capaz de hacer medible su desempeño y de dar cuentas del mismo.

Antonio Vives (2003), encargado del BID para los programas de RSE elabora un diagrama para identificar la forma en que diferentes conceptos se relacionan entre sí en la RSE (ver Fig.1). Según este diagrama, la RSE es un concepto que va más allá de la suma de sus partes: ética, cumplimiento de la ley, gobernabilidad corporativa, filantropía y filantropía estratégica. La ley está en el centro, al igual que la ética. RSE, incluye asimismo, una parte de la filantropía, pero deja claro que no toda acción filantrópica es socialmente responsable, sino solamente aquella que está ligada a las estrategias de la empresa y se excluyen de esta clasificación a los donativos eventuales. La RSE, finalmente, tiene que ver con el manejo de acuerdo a las normas de buen comportamiento corporativo contemplados en el concepto de gobernabilidad empresarial. Es decir, asuntos que pueden o no estar en las leyes pero que deberían ser de cumplimiento obligatorio, tales como el rechazo prácticas de corrupción, evasión de impuestos, tráfico de influencias, manejo transparente de las cuentas de la empresa frente a actores interesados, etc. Desde este punto de vista, una empresa que hace filantropía, pero que no se apega a la ley o que se aprovecha de normativas débiles para cometer acciones reñidas con la ética, no estaría siendo socialmente responsable. 


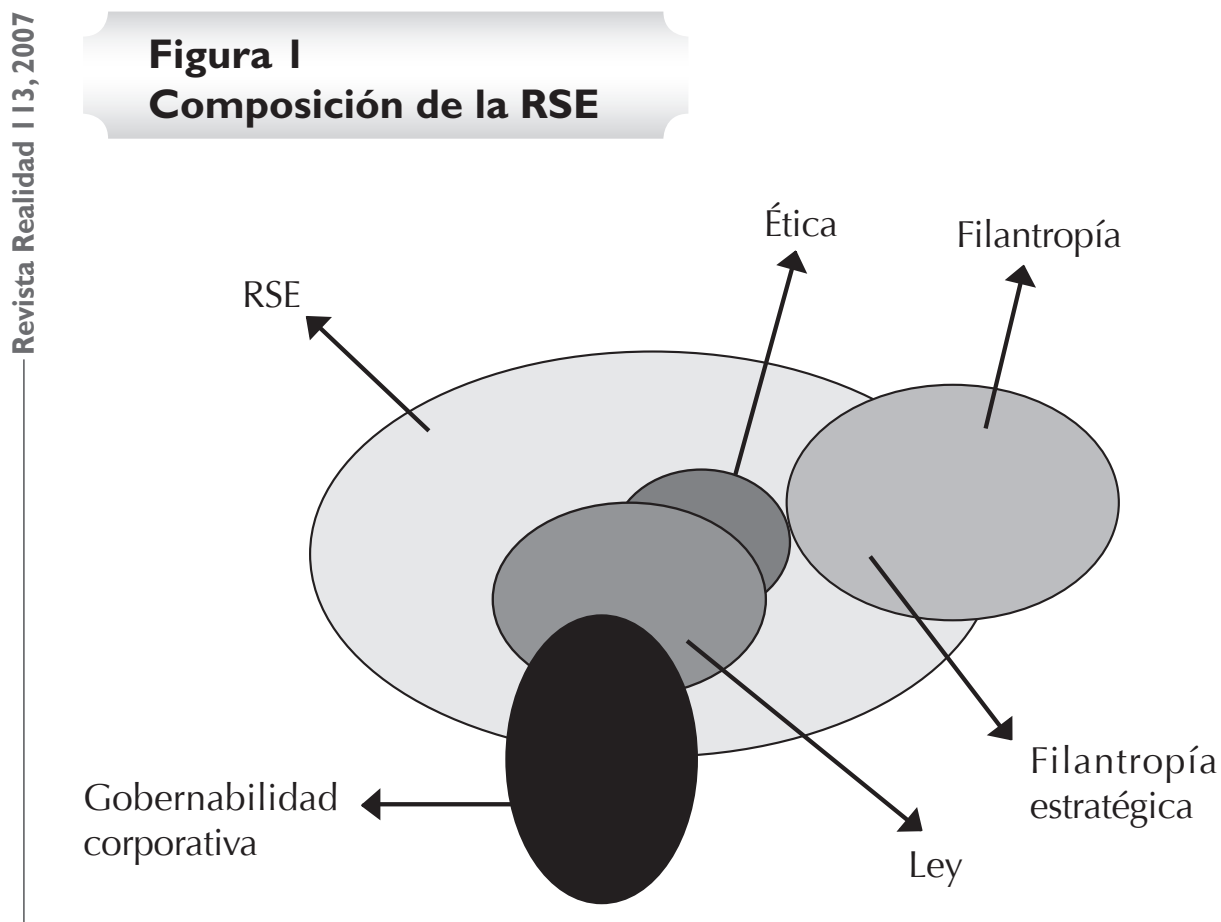

Con base a todas estas afirmaciones, Bull elabora un concepto de RSE de la siguiente manera:

"Mi definición de RSE enfatiza tres áreas principales: a) Iniciativas de la compañía para reducir los efectos negativos que su actividad pueda ocasionar o incrementar los efectos positivos de la misma, b) Acciones de las empresas para mejorar la calidad de vida de sus contrapartes primarias (trabajadores, inversionistas y dueños, consumidores y comunidad) y secundarias (estado, organizaciones sociales) y c) Los esfuerzos de las empresas en incluir un código ético en su gobernabilidad corporativa".

Adicionalmente, la empresa debe dar cuanta de las cuestiones sobre las que está haciendo y trabajo de incidencia. Si está haciendo propuestas de leyes o está ejerciendo sus influencias para impulsar determinadas políticas públicas, debe hacerlo de manera pública. 


\subsection{La RSE como herramienta de autorregulación}

La responsabilidad social empresarial remite a discusiones sobre autorregulación de la actividad empresarial y desde este punto de vista se nos presenta como un concepto complejo y controversial. No hay un consenso de lo que significa y de cuál es su trascendencia y por otro lado, las opiniones que genera el pensar en empresas que se autorregulen son tan diversas como enfoques existen.

Sobre este tema hay opiniones que califican el término y su uso como un mero acto de mercadotecnia. Otros, más bien lo evalúan como un signo de nuevos tiempos y un instrumento de gran poder de transformación social. Hay quienes sostienen que las empresas no son capaces de autoregularse y que la tarea de velar por que se comporte de acuerdo a parámetros mínimos de convivencia le compete al Estado y a los sindicatos. Por otro lado, otras opiniones manifiestan que éstas tienen una capacidad inmensa de establecer sus propios límites y que el altruismo y la decencia son también parte de la vida empresarial.

Ciertamente, ante los escándalos de corrupción de diversas empresas y la exposición de actos controvertidos ejecutados por compañías en diversas partes del mundo, es muy difícil pensar que las empresas logren regularse por sí mismas de una manera efectiva. Los gobiernos, sindicatos, organizaciones sociales, instituciones de regulación internacional, etc., deben colaborar para asegurar que las empresas cumplan con algunos requisitos de desempeño mínimo.

Los intentos de autorregulación no son inútiles en absoluto, pero la evidencia da cuenta que hacen falta instancias reguladoras externas para vigilar que la actividad empresarial no resulte en efectos negativos para otros. Los gobiernos han debido establecer un marco para esta actividad, ciertas instancias internacionales buscan establecer reglas globales para la actividad comercial, muchas organizaciones sociales están demandando cada vez más transparencia a las empresas y los consumidores hacen sentir su interés en el desempeño de las compañías.

Sin embargo, resulta una novedad que las mismas empresas estén replanteándose su papel en la sociedad y asumiendo que además de derechos, tienen responsabilidades con su personal y con su entorno. En esta novedad también hay controversia y más allá de la definición del concepto y sus alcances, aún hay preguntas sin contestar, tales como la relación entre las iniciativas de autorregulación empresarial y el Estado, las relaciones entre iniciativas de RSE y organizaciones sociales, el "business case" de la RSE (es decir ¿es posible generar ganancias a partir de RSE?) entre otras. 
El interés por regular la actividad empresarial no es nuevo en absoluto. Desde 1930 hay antecedentes de intentos de autorregulación en las empresas textiles en los EE.UU. Eran momentos de fuertes crisis económicas en ese país y la adopción de un código de conducta para la industria (registrado como el Acta de Reconversión de 1933) resultaba una medida de protección frente a la competencia desleal. En este caso, los actores comprometidos fueron las empresas textiles y el gobierno estadounidense.

Posteriormente, en la década de los años setenta hay nuevos intentos por regular la actividad de las empresas, pero en esta ocasión, las empresas sujetas de revisión eran las empresas transnacionales y los entes encargados eran instancias internacionales como Naciones Unidas. La atención estaba puesta en la relación entre la casa matriz y sus empresas colocadas en terceros países. Uno de los hitos de este momento, fue la elaboración de las Guías de Comercio Internacional (OCDE, 2000). Éstas intentaban normar las actividades de las empresas transnacionales frente a gobiernos en donde establecían plantas. Las guías de la OCDE retoman los principios fundamentales de la OIT: libertad de asociación y negociación colectiva, abolición del trabajo infantil, eliminación de trabajo forzoso y no discriminación. En su elaboración participaron sindicatos internacionales y empresas.
En 1977, las Naciones Unidas a través de la Organización Internacional del Trabajo prepara la Declaración Tripartita de Principios en lo concerniente a las Empresas Multinacionales y la Política Social. Los énfasis estaban puestos en la soberanía nacional y tripartismo como mecanismo de solución de conflictos y toma de decisiones. Esta declaración es retomada en 1998 y alimentada con nuevos elementos. Para ese año, el documento se nombra como Declaración de los Principios Fundamentales y de los Derechos del Trabajo (OIT 1998). En 1992, las Naciones Unidas elaboran un código de conducta para las corporaciones transnacionales

Para la década de los años noventa, las empresas ya no estaban operando bajo el sistema de casa matriz y empresas subsidiarias, sino más bien, bajo modalidades de eslabonamientos productivos entre procesos diversos segmentados incluso geográficamente y a nivel global. En este esquema, las multinacionales no necesariamente son dueñas de las empresas que trabajan para ellas y el control de la producción se hace por la vía de contratación y subcontratación de proveedores, contratistas, subcontratistas, licencias, etc. La regulación de estas empresas se complica y se inicia una nueva fase en la búsqueda de mecanismos de aplicación de reglamentos. Es en este momento que nacen los códigos de conducta corporativos y los códigos multisectoriales. 


\subsection{Códigos de conducta}

Los códigos de conducta corporativos son compromisos adquiridos por las empresas para asegurar un mínimo de cumplimiento a derechos laborales, ambientales y otras buenas prácticas a lo largo de su cadena de suministros en cualquier lugar del mundo. Son de cumplimiento obligatorio para todos sus proveedores, suplidores, contratistas y subcontratistas.

Los códigos de conducta multisectoriales más bien son regulaciones elaboradas con participación de diversos actores interesados tales como sindicatos, ONG, gobiernos y empresas transnacionales. Pretenden abarcar la industria completa y no sólo a una empresa. Los más conocidos en son el de la Asociación de Trabajo Justo (FLA, por sus siglas en inglés), el Consorcio de Derechos de los Trabadores (WRC, por sus siglas en ese mismo idioma) y la norma Social Accountability (SA) 8000. Sin embargo, hay algunas otras iniciativas europeas tales como la Iniciativa de Comercio Ético (ETI) y la de Campaña de Ropa Limpia (CCC).

La FLA reúne a las empresas más grandes de ropa en los EE.UU., tales como Reebok, Nike, Liz Claiborne, Phillips, Van Heussen, Adidas, entre otras. La FLA fue el primer código multisectorial en la industria de la ropa y la indumentaria. Sus orígenes se remontan a 1996 con la Apparel Industry Partnership (AIP), fundada por la Ad- ministración Clinton en los EE.UU. con la participación de empresas, sindicatos y ONG. Posteriormente, los sindicatos y varias ONG se separan de la AIP, ante la imposibilidad de concertar sobre temas álgidos tales como el salario para vivir y el monitoreo independiente.

EI WRC es una iniciativa derivada de los estudiantes universitarios aglutinados en United Students Against Sweatshops (USAS) y el sindicato estadounidense de la industria textil UNITE. Su universo de trabajo son las ropas con licencias de las universidades miembros y su código de conducta requiere de una divulgación completa de las fuentes en que se elaboran los productos.

Por su parte, la SA 8000 representa uno de los códigos de conducta con más altos estándares, formulado dentro de una alianza amplia de $O N G$, sindicatos y empresas, entre las que destacan Amnistía Internacional, la Federación Internacional de Trabajadores de la Industria del Vestuario, Calzado y Cuero; Toys "R" Us, entre otros. La SA 8000 retoma elementos de gestión comprendidos en las Normas ISO.

En esta fase del desarrollo empresarial, las compañías diseñen sus propios mecanismos de regulación, sin que ello exima a los Estados y a otros actores (como las ONG y los sindicatos) de la responsabilidad de vigilar los cumplimientos. La regulación apegada a RSE resultaría de la coordinación entre diversos actores interesados: empresa, estado, ONG y sindicatos. 
El público consumidor, es también un actor en esta regulación. Si bien no actúa directamente como grupo (en buena medida por las dificultades inherentes a la organización de un sector relativamente difuso como el "consumidor"), algunas organizaciones de consumidores sí son parte de las discusiones sobre la regulación y monitoreo de las prácticas de RSE.

De hecho, el interés por la RSE comenzó a gestarse en la década de los años sesenta ante la presión del público consumidor. En sus primeras fases, las exigencias se centraban en una mayor transparencia sobre la calidad de los productos que se ponían en el mercado y la exposición de los componentes de los productos, especialmente alimenticios. Posteriormente, los consumidores demandaban a las empresas que sus actividades no dañaran al medio ambiente, especialmente en lo que se refiere a la conservación de bosques y al cuidado de los animales.

Las etiquetas de productos reciclados, "no probado en animales", "sin daño a los delfines", entre otros, comienzan a proliferar en esta etapa, especialmente en los países más industrializados. Finalmente, a mediados de la década de los años noventa el interés en la RSE se vuelca al campo de los derechos humanos y particularmente al énfasis en los derechos laborales. En esta nueva ola, sin embargo, también han intervenido los inversionistas. Tanto en Europa como en EE.UU. se ha constituido un movimiento muy intenso liderado especialmente por iglesias que presionan para usar el poder de las inversiones de una manera responsable. En EE.UU., el $10 \%$ de los fondos de inversión en la bolsa de valores se maneja con criterios sociales y los inversionistas de manera cada vez más frecuente, analizan las empresas en que invertirán fijándose en el desempeño de éstas en temas ambientales y de derechos humanos (Gearthard, 2001).

Ciertamente, este concepto de consumidores demandantes de buenas prácticas es más frecuente en países donde el poder adquisitivo del consumidor permite hacer presión a las grandes empresas. En este sentido, no es extraño que la RSE sea más frecuentemente aplicada en industrias centroamericanas que se dedican a la exportación, más que en empresas que trabajan para consumo doméstico. El consumidor centroamericano, aún no tiene un poder de compra tal que induzca cambios en la actuación de las grandes empresas (Fintel y Pratt, 1997).

En suma, la RSE es un concepto que ha llegado para quedarse. Aún no hay consenso sobre sus alcances y sus limitaciones, pero es cada vez más aceptado que las empresas requieren instrumentos de regulación global que consigan no sólo frenar las externalidades generadas sino potenciar las ventajas de la actividad económica y comercial para las personas y la comunidad. 


\subsection{Comercio justo}

El tema de las buenas prácticas es relativamente reciente en la industria de la ropa, pero es ciertamente, un tema que ha venido cobrando importancia también en otros sectores productivos. La presión de los activistas ha contribuido grandemente a generar un público consumidor cada vez más consciente de su poder de provocar cambios en las actitudes de las empresas. No todos los casos se han resuelto y muchas empresas aún no terminan de convencerse de poner más vigilancia en su desempeño sobre derechos humanos. Más aún, en las mismas empresas que ya han iniciado procesos para una mayor responsabilidad hacia su personal y medio ambiente, enfrentan fuertes resistencias internas que no siempre son fáciles de manejar. Sin embargo, es inobjetable que el mercado y particularmente un público consumidor informado pueden contribuir a hacer cambios.

Uno de los sectores donde esta intervención de un público consumidor informado y decidido a hacer valer su poder de compra, es dentro del Ilamado comercio justo. El comercio justo es un concepto menos nuevo que la RSE. Sus orígenes se remontan finales de la década de los años sesenta en Europa y su surgimiento es el resultado de una profunda crítica ante las consecuencias del comercio mundial en países pobres. Se parte de la afirmación de que la pobreza en al- gunos países es causada en buena medida por reglas inequitativas en el comercio mundial. Los países pobres dependen de la exportación de materias primas, bienes cuyo precio disminuye constantemente en el mercado mundial, mientras los precios de los bienes manufacturados tienden a subir. Se hace necesario revertir esta lógica del intercambio y pagar a los productores pobres un precio que les permitiera construir su propio desarrollo. Esta propuesta resalta que para superar la pobreza se requiere de más comercio bajo reglas justas y de menos caridad. El lema es: "Comercio, no asistencia".

El comercio justo se presenta como una práctica alternativa a las redes de comercio tradicional y una acción solidaria frente a los productores pobres. Consiste en asegurar a pequeños productores un precio adecuado que compense los costos de producción y que genere un salario digno. Bajo la aplicación de este concepto, se eliminarían intermediarios entre el productor y el mercado, se aseguraría la compra de bienes y la colocación de los mismos en tiendas minoristas, se fomentaría la asociación y organización de pequeños productores así como se educaría al público consumidor para que ejerza su poder de compra de tal manera que genere cambios en las reglas del comercio. Los criterios de elegibilidad para vender producción bajo el concepto de comercio justo son: asegurar salarios dignos para los productores, eliminar la explotación infantil, cuidar el medio ambiente, fomentar 
igualdad entre hombres y mujeres y respetar derechos laborales (Intermon, 2003).

Los productos que se comercializan bajo este sello, fueron vendidos originalmente a pequeña escala en tiendas montadas por organizaciones solidarias. Sin embargo, luego de más de 30 años, la venta de productos de comercio justo se comienza a realizar fuera de estas pequeñas tiendas para alcanzar cada vez a un público mayor y ampliar los beneficiarios de este intercambio. Este cambio no estuvo exento de críticas y desacuerdos, ya que colocar productos en tiendas grandes y hacer tratos con empresas transnacionales, no es un asunto fácil de asimilar para los más críticos. Sin embargo, la necesidad de ayudar a más grupos pobres a colocar sus productos y obtener ingresos, obligó a estos giros pragmáticos. Este proceso coincidió con la crisis de los precios internacionales del café y es así cómo, el comercio equitativo se convierte en una oportunidad para los productores pobres del grano.

En el caso del café, donde los bajos precios de compra han em- pobrecido aún más a los pequeños productores, el comercio equitativo ha significado una ventana de oportunidad, ya que los productores obtienen un mejor precio por su café y mejores oportunidades de subsistencia, gracias a su participación en estas iniciativas. Algunas empresas especializadas de café en los EE.UU., como Starbucks, Dunkin' Donuts, Procter and Gamble e incluso Kraft, han incluido líneas de café equitativo a su repertorio cafetero. Pese a que el comercio justo es aún pequeño en comparación con el consumo global, es un sector en crecimiento. El consumo de café justo creció a un $12 \%$ en el 2001, en comparación con el crecimiento promedio mundial de consumo de café en ese año que fue de un $1.5 \%$ (Oxfam Internacional, 2002).

El auge del comercio justo permite hacer algunas comparaciones con otras industrias y argumentar que existe un mercado para bienes fabricados en buenas condiciones. Las empresas podrían tener mejores posibilidad de mantenerse en el mercado, posicionándose como productores respetuosos de los derechos humanos. 


\section{3. ¿Por qué la industria necesita la RSE? EI caso de la industria de ropa.}

"Una buena marca es el Santo Grial de una empresa".

Scott Bedbury, responsable de la campaña "Just do it" de Nike

L

iz Claiborne, Phillips-Van Heusen, Sears, JC Penney, Wal-Mart, entre otras, son empresas de ropa con ventas miIlonarias en EE.UU., Canadá y Europa que basan su éxito comercial en la promoción de su marca. Estas compañías, ejemplo por excelencia de cadenas de producción global orientadas por el consumo, no fabrican la ropa que venden, sino más bien se centran en las actividades de la cadena productiva en las que se generan las mayores ganancias: el diseño y la comercialización. La fabricación de la ropa la encargan a otras empresas y así además de abaratar costos, pueden deslindarse de todos los inconvenientes que tiene la producción de mercancías y dedicarse a donde realmente esta la fuente de sus ingresos: la venta directa al consumidor, ya sea en tiendas de ropa especializada (como las de Nike, Levi's, Gap, etc.) y/o en grandes almacenes (Wal-Mart, JC Penney, Sears, etc.).

Los almacenes de ropa especializada, las tiendas por departamentos y los vendedores minoristas, se ubican a la cabeza de la cadena productiva, no sólo en términos de ganancias sino, sobre todo, en la posibilidad de dirigir la producción, aunque no posean fábrica alguna. La suerte de los miles de productores y proveedores está determinada por las decisiones de estos vendedores minoristas y las grandes marcas (Gereffi, 1995).

Para comercializar sus productos, estas empresas deben presentarlos al público consumidor y es aquí donde el mercadotecnia aconseja ir más allá de la descripción de las cualidades del bien y explotar la marca como un concepto, en el cual, la imagen es lo que cuenta.

Scott Bedbury, responsable de la campaña de Nike y Starbucks, insiste en que para posicionar una marca es básico conectarse emocionalmente con el cliente. "El mundo está lleno de buenos servicios y buenos productos y es necesario centrarse en qué es lo que nuestros productos o servicios hacen sentir al consumidor... El concepto "Imagen de marca" es complejo en la actualidad. En otras épocas, para definirlo se utilizaban términos físicos, por ejemplo: más rápido, brillante, más 
duradero, de mejor calidad. Ahora, la imagen de una marca tiene que ver con su comportamiento en el medio ambiente, con los servicios que realiza con su comunidad, con los informes de integridad financiera o con la moral de los altos directivos de la empresa" (Peñaroya, 2004).

Por su parte, el Vicepresidente de Mercadotecnia de Starbucks, una importante cadena de cafés en los EE.UU., sostiene que "Ios consumidores no creen verdaderamente que haya una gran diferencia entre los productos y por eso, las marcas deben establecer relaciones emocionales con sus clientes" (Klein, 2001, p. 47-48)

La marca ya no aparece como un artículo de consumo, sino como una experiencia o un estilo de vida. Nike ha trabajado duro para convertirse en el símbolo del estilo de vida sana y el deporte como modo de destacarse y/o de integración social, Benetton en la imagen de lo alternativo y el "compromiso" con causas tales como la no discriminación racial; Tommy Hilfiger, como expresión de la diversidad racial que compone la nación estadounidense, Adidas, como promotor del fútbol en el mundo, etc.

Aparentemente, en una sociedad de consumo la gente no compra un producto necesariamente por su utilidad. Lo compra porque el producto lo refiere a una experiencia o a un estilo de vida del cual quiere formar parte. La relación con el producto se da a nivel de conceptos abstractos, tales como la vida sana, la rebeldía, la autoafirmación femenina, la pasión por el fútbol, entre otros, y no necesariamente a través del valor de uso del bien.

Es bien conocida esa faceta del consumismo de preferir marcas antes que productos y la capacidad que tienen algunas personas (incluso de escasos recursos económicos) de gastarse una pequeña fortuna en artículos que probablemente en nada se diferencian de otros con etiquetas menos conocidas.

En Centroamérica, donde la falta de ingresos impide estos gastos, se recurre a la piratería y no es raro encontrarse con falsificaciones de etiquetas en prendas de ropa elaboradas sin licencia. "No es lo mismo" usar una camiseta signada por un sello desconocido a una de marca famosa, aunque ésta sea pirateada. Las marcas, además de la identificación con algún elemento sugerente para la vida actual, generan además cierta noción personal de estatus e integración social, especialmente en sectores que no han asistido a procesos de integración social con referentes identitarios tradicionales y que han estado expuestos a la cultura consumista, donde el Ser pasa por el consumo (Sojo y Pérez Saínz 2002).

Algunos autores sugieren incluso, que en el afán de promocionar marcas, el mercadotecnia se ha convertido en el nuevo formador $y$ socializador; tomando el papel que antaño le competía a la escuela, la iglesia y la familia. De esta forma, 
las marcas nos acompañan más allá de la experiencia de comprar y usar un producto: son parte de la formación de identidades comunitarias y personales. Según Jeremy Rifkin, "el comprar una marca transporta a los compradores hacia un mundo imaginario; tienen la sensación de que realmente comparten con otros los valores y significados creados por los diseñadores".

Para Rifkin, estamos asomando una era en la que pagamos más por la experiencia de usar cosas que por el valor y la utilidad que las cosas tienen en sí mismas. En la era que se abre, especialmente en los países ricos, "las relaciones mercantilizadas con los consumidores se convierten en el negocio esencial de los negocios; controlar al cliente es ahora algo tan importante y tan urgente como en tiempos en que dominaba la perspectiva de la manufactura lo fue el control sobre los trabajadores... En el siglo venidero, la organización del consumo será tan importante como en el siglo pasado lo fue la organización de la producción" (Rifkin 2000. 144-145)

El producto se transforma en un símbolo de alguna cosa que sea lo suficientemente valiosa para ser vivida. La gente recurre a los productos no solamente para satisfacer una necesidad inmediata, sino para experimentar esas cosas que la mercadotecnia le han prometido. Esto es especialmente visible en los productos de diseñador y en las marcas, pero lo es también para otros bienes que no habían sido objeto de aproximación simbólica, tales como los alimentos. Los productos alimenticios no sólo son fuente de energía, sino que incorporan asimismo valores simbólicos que marcan estatus. Con el consumo de ciertos productos, las personas también expresan los valores con que se identifican y ésta es una buena parte de la clave del creciente éxito de los productos orgánicos y de comercio justo (Renard, 1999).

Probablemente, al igual que la ropa de marca, en Centroamérica aún no es tan visible el gusto por productos orgánicos o de comercio justo y, probablemente, sea un poco difícil imaginar que los alimentos tengan un valor más simbólico que material. Esto no tiene nada de extraño, ya que ante los niveles de pobreza de nuestros países, la mayoría de la gente no puede permitirse escoger sus alimentos con base en gustos, vivencia de experiencias, declaración de valores y/o delimitación de estatus.

Sin embargo, los centroamericanos, a nuestra manera, sí hemos vivido de una forma particularmente intensa la peculiaridad de percibir los productos alimenticios como símbolo y como experiencia, especialmente en el caso de los Ilamados productos nostálgicos. Los aviones que viajan de Guatemala o El Salvador hacia los EE.UU. están siempre con olor a comida entre la que destaca el pollo frito, (ies que no hay suficiente pollo frito en los EE.UU.?) y las maletas de los viajeros, llenas de quesos, cremas, ta- 
males y otros productos de nuestra tierra, que son las delicias de los centroamericanos en los EE.UU. Sin mencionar el caso de las pupusas y de las protestas que caldearon los ánimos en las negociaciones sobre el CAFTA, ante las declaraciones de Honduras de que pretendía certificar tal platillo como producto hondureño (GMIES 2003).

Los productos nostálgicos tienen un mercado asegurado con nuestros compatriotas en el extranjero porque les hacen revivir la experiencia de cercanía a su patria, a sus parientes, amistades y a lo que consideró suyo desde siempre. Los alimentos pues, también se han contagiado de esta fiebre capitalista del consumo de experiencias más que el consumo de los bienes en sí mismos, aún en países pobres.

Debido en buena medida a las estrategias empresariales para agilizar la realización de su producción y a la falta de otras alternativas de integración social, el público consumidor se ha vuelto un actor con un peso propio y con cierto protagonismo frente a las compañías multinacionales. El consumo y su referente, el público consumidor, especialmente en los países ricos, ha adquirido una relevancia innovadora en la era de la globalización, situación que no ha pasado inadvertida para los activistas de derechos humanos.

La imagen de las marcas que constituye la piedra en la que se construyen las grandes compañías de indumentaria es, asimismo, su Talón de Aquiles y esta vulnerabilidad ha sido aprovechada por los activistas laborales alrededor del mundo para exigirles cuentas sobre el trato que reciben las personas que elaboran sus mercancías. Algunas de estas empresas ya han comenzado a escuchar.

Los grupos de activistas laborales en los países consumidores han descubierto que una forma efectiva de involucrar a las grandes compañías en la resolución de problemas en las fábricas maquiladoras es, precisamente, comprometiendo su imagen y afectado sus ventas. En el caso de algunas empresas como Nike, que ha estado expuesta a múltiples campañas de denuncia sobre malas condiciones de trabajo en sus fábricas proveedoras, las ventas se redujeron sensiblemente luego de 1995 (año pico en materia de denuncias) y los beneficios trimestrales se redujeron en un $70 \%$ hasta 1999 , en que éstos rendimiento se recuperaron. Sin embargo, esta mejora no aparece como producto de un alza en las ventas, sino a costa (según la misma empresa) de una reducción de personal y de contratos (Klein, 2001 p. 436).

Klein también da cuenta de otros casos en los que el poder del público consumidor logró estremecer a algunas compañías tan grandes, que parecían intocables hace apenas algunos años. Una de ellas es Royal Dutch/Shell, que luego de una campaña orquestada por Greenpeace para denunciar el daño que 
esta empresa ocasionaría al medio ambiente al desechar en el fondo del mar una antigua plataforma de almacenamiento, reportó bajas en sus ventas de gasolina entre un 20 y un $50 \%$ en Alemania y otro tanto en Gran Bretaña, Dinamarca, Austria y Holanda. En palabras de altos ejecutivos de esta empresa — según cita Klein-, esas consecuencias fueron "lo peor que hemos pasado" (op. cit., p. 439). Finalmente Shell cedió a las demandas de los activistas, convirtiendo esta campaña en un caso sin precedentes.

Los investigadores alemanes Werner y Weis (2003) dan cuenta de una serie de irregularidades encontradas en proveedores de diferentes compañías multinacionales y cómo estas empresas reaccionaron a las demandas de grupos de activistas. En casi todos los casos las compañías han respondido a las presiones. Si bien, no siempre las respuestas son las que los activistas esperaban y muchas de ellas resultan ser meras estrategias de mejoramiento de imagen, lo cierto es que los descubrimientos de problemas de malos tratos al personal, daños al medio ambiente o complicidades con gobiernos corruptos sí tienen mella en la conducta de las empresas y éstas buscan de una u otra forma resarcir los daños y/o buscar algunas formas de mayor control sobre sus proveedores. De los casos que mencionan Werner y Weis, la gran mayoría de las críticas han derivado en la instauración de códigos de conducta y de algún mecanismo de monitoreo del mismo ejecutado, eso sí, por la misma empresa en casi el $100 \%$ de los casos que el libro aborda.

Luego de 1995, el año en que aparecieron más protestas en los medios estadounidenses, muchas empresas de ropa se sumaron a iniciativas de responsabilidad social. Crearon o tradujeron sus códigos de conducta a los idiomas de los proveedores locales y establecieron que todas las empresas con quienes se relacionan a lo largo de su cadena de producción, debían cumplir con tales disposiciones. A la fecha se han contabilizado cientos de códigos de conducta y cada una de estas empresas tiene (o debería tener), un sistema de monitoreo de los mismos.

Las protestas están Ilamando cada vez más la atención del público consumidor y han provocado que las marcas pongan más esfuerzo en mejorar su desempeño en el cumplimiento de sus propios códigos. Según algunos investigadores, el consumidor o consumidora promedio piensa más o menos así: "realmente no quiero enterarme que mis ropas están hechas en malas condiciones. Pero si me doy cuenta, quiero que las condiciones mejoren para poder disfrutar otra vez del consumo de este producto". La razón por la que las campañas logran tener efectos disuasivos es porque al público consumidor sí le importa (Elliot y Freeman, 2000).

Ciertamente este interés no es el mismo para todas las marcas y algunas han respondido mejor que otras a las presiones, especialmente 
aquellas que basan su estrategia de mercado en la promoción de su propia imagen y no en bajos precios.

En estos casos, estas marcas demandan de sus proveedores el cumplimiento de los códigos de conducta de la marca o de las instancias multisectoriales $y / o$ voluntarias en las que las marcas estén involucradas ${ }^{2}$. Los códigos y el cumplimiento de los mismos es visto como una estrategia para reducir el riesgo de que la reputación de la marca se vea afectada por denuncias. Un suplidor que no esté respetando los derechos de sus trabajadoras puede dañar significativamente la imagen de la marca, afectar sus ventas y el valor de sus acciones en el mercado. En ese sentido, los mismos suplidores ven sus cumplimientos como un prerrequisito para formar parte de la cadena global de suplidores de ciertas marcas, especialmente de aquellas que son más atractivas para el público consumidor. En ciertos casos, mantener buenos estándares sociales y ambientales podría generarles acceso a otros clientes y obtener contratos de trabajo más estables e incluso algunas tarifas premiun.

Hay noticias de empresas tales como Nike y Adidas catalogan a sus proveedores según su desempeño en diferentes áreas, pero otorgan dobles puntos por cumplimientos en materia social y ambiental. Los suplidores de Nike con puntajes más altos ganan los mejores contratos y los de puntajes más bajos, los pierden. Ciertamente, muchos de estos monitoreos son realizados por la misma empresa y la opinión pública (la mayoría de las veces, con razón) no siempre confía en las autoevaluaciones, pero es destacable cómo el tema del cumplimiento en RSE se vuelve parte de las preocupaciones de las marcas y de los proveedores (O'Rourke, 2003).

Levi Strauss, por su parte, se convirtió en la primera compañía en elaborar un código de conducta de cumplimiento obligatorio para sus licencias y es una de las empresas que más énfasis ha puesto en que el cumplimiento de su código de conducta es un criterio relevante para establecer negocios. Los dictámenes de los inspectores de cumplimiento se toman en cuenta en el departamento de compras.

Gap, otra empresa que ha mejorado notablemente su atención a derechos laborales y ambientales, dio cuenta de un ejercicio de transparencia inédito en la industria al exponer de manera muy amplia la situación de cumplimiento en sus proveedores y de las acciones que está tomando para que el código de conducta sea incorporado plenamente a las estipulaciones básicas de las relaciones de negocios que establecen. Gap menciona, por ejemplo, que "en el 2003 revocaron la aprobación de 136 fábricas" y que algunas de las empresas de indumentaria con quienes trabajan optaron por dejar de hacer negocios con ellos por considerar que los estándares eran demasiado altos. En su intento de vigilar el cumplimiento de sus estándares sociales, Gap presenta una notable tra- 
yectoria en el trabajo conjunto con organizaciones locales, activistas en el Norte, organizaciones multisectoriales en los países consumidores y organizaciones de monitoreo independiente.

Este creciente interés de las marcas en la RSE y en el cumplimiento de códigos de conducta, se ve reforzado por algunos estudios realizados en los EE.UU. que sostienen que al menos el $80 \%$ de los consumidores estarían dispuestos a pagar más por un producto si se le garantiza que ha sido elaborado bajo buenas condiciones. Los consumidores evitan comprar productos de empresas de mal comportamiento o con escándalos sobre violaciones a los derechos humanos de sus trabajadores. En el 51\% de los casos, según estas encuestas, el público consumidor estadounidenses ya ha "castigado" a alguna empresa que se haya vista en medio de un escándalo por violaciones a los derechos humanos (O'Rourke, 2003).

Ciertamente, no todos los esfuerzos han cuajado en mejoras sustantivas en las condiciones de trabajo en las empresas. La organización inglesa Ethical Trade Initiative que congrega a varias empresas transnacionales, ONG y sindicatos, sostiene que luego de 8 años de aplicación de códigos de conducta, si bien ha conseguido cambios en algunos elementos tales como trabajo infantil y seguridad e higiene, no han tenido aún mucho éxito en libertad sindical y en mejores condiciones salariales (FT, 2007)

\section{4. ¿Es factible plantearse a la RSE como estrategia?}

A Igunas investigaciones sobre la aplicación de principios de RSE en temas de medio ambiente (Fintel y Pratt, 1997) en CA señalan que en general, existe poca inversión en esta materia, pese a que la aplicación de ciertos de estos principios - como la reducción de gastos de energía y agua, mejor disposición de la basura, etc.- - inciden notablemente en una reducción de costos en la empresa.
Algunas de las razones que este estudio da para tan escaso interés, son la falta de conocimiento sobre las ventajas del manejo ambiental y el marco institucional que no estimula las buenas prácticas. Según este estudio, hay poco material disponible y hay muy pocas organizaciones dispuestas a difundir las ventajas de las prácticas "verdes". Adicionalmente, las empresas trabajan con visiones de muy corto plazo y 
no están interesadas en el manejo de programas cuyas ventajas no serán vistas de inmediato.

El marco legal no parece tener un efecto disuasivo suficiente para motivar las buenas prácticas, no hay incentivos fiscales a empresas con manejo de programas ambientales sostenibles ni para la adquisición de tecnologías o equipos productivos menos contaminantes $y$, finalmente, el sistema financiero existente tampoco apoya inversiones en manejos ambientales responsables.

Probablemente, estas mismas limitaciones se aplican en otras áreas de la RSE, tales como el manejo de los derechos laborales, la rendición de cuentas por parte de las empresas, el trabajo coordinado con otros actores interesados, entre otros.

En la maquila de ropa y textiles en Centroamérica hay problemas adicionales: Falta de claridad por parte de muchas de las firmas compradoras para colocar la RSE y el cumplimiento con el código de conducta al mismo nivel de importancia que otras condiciones de calidad, tiempo y precio, así como falta de incentivos comerciales a las empresas sobre cumplimiento de principios de RSE. Todo ello, además de la posibilidad siempre abierta de que en caso que un cliente sea demasiado exigente, la fábrica pueda moverse hacia un cliente menos estricto.

De hecho, los clientes que exigen poco o nada en materia de cumplimiento de códigos de conducta o en RSE parecen ser la generalidad.
Las marcas menos conocidas y que operan en las tiendas de descuento, suelen reportar niveles bajísimos de respeto a derechos laborales y otros y algunos sostienen que las prendas de vestir baratas, lo son a un costo humano altísimo (FT, 2007)

Paralelamente, encontramos problemas en la multiplicación de códigos y de sistemas de monitoreo que no son compatibles y que muchas ocasiones permiten no sólo evadir la responsabilidad sino hacerlo avalado por el Estado, así como en la cultura empresarial cortoplacista donde sólo se buscan reducir costos - en muchos casos sin consideración a las personas que saldrán afectadas de este movimiento- como forma de mejorar la productividad; la falta de una cultura democrática y de respeto a derechos; y la falta de cultura de rendición de cuentas, entre otras.

Sin embargo, esto debería de cambiar, ya que la Centroamericana tiene en la RSE una ventana de oportunidad, aún sin explotar. Las marcas están interesadas en mantener contratos con empresas en cumplimiento de RSE. Si bien no es la única razón para quedarse o irse de un país o de un socio, es ciertamente una de las principales cuestiones a considerar.

Por su parte, los consumidores están cada vez más interesados en adquirir bienes que sean hechos bajo buenas condiciones laborales y ambientales y/o en castigar las marcas con fama de deficien- 
tes desempeños en RSE. Adicionalmente, hay experiencias exitosas en las que el tema comercial aparece ligado a la RSE con muy buenos resultados para la industria y los empleos que dependen de la misma y, lo más importante, una verdadera cualificación industrial y un impulso real al desarrollo viene acompañado de una mayor preocupación en las personas.

En esta era, los consumidores son una poderosa fuerza con capacidad de hacer que cambie el estado de las cosas y modificar las reglas del comercio. Con su poder de compra puede elegir un bien que se haya producido bajo condiciones justas y está creando un lugar en el mercado para otras posibilidades de comercio en donde sea el trabajador el centro de la actividad y el más beneficiado. El consumidor comprometido, tiene la posibilidad de hacer cambios en las reglas del juego del comercio mundial y las empresas parecen responder a este interés. Las empresas están comenzando a visualizar que esta es una fuerza que no se puede ignorar. La RSE y los intentos de regulación y autorregulación en las empresas globales son una de las ideas ganadoras, pero para ver sus alcances, hay que asumirlas en serio.

No llegaremos muy lejos si seguimos promocionando a la región como un espacio de mano de obra barata y no calificada. La forma más segura de mantenerse en la pobreza, es vender pobreza y ya llegó el momento en que el sector privado en Centroamérica abandone este discurso.

\section{Bibliografía}

- Bull, B. (2003) "Corporate social responsibility: The Norwegian Experience". Documento preparado para la Iniciativa sobre ética y desarrollo, Banco Interamericano de Desarrollo.

- Elliot K.A. y Freeman R. (2000) "White Hats or Don Quixotes? Human Rights Vigilantes in the Global Economy". NBER Conference on Emerging Labor Market Institutions, August, 2000. http://www.nber. org/ confer/2000/si2000/elliot.pdf

- $\quad$ Fintel E. y Pratt, L. (1997) "Environmental Management as an Indicator of Business Responsibility in Central America” Incae, CEN 701. San José, 1997

- Financial Times (2007) "La responsabilidad de tener las manos limpias". 16 de enero de 2007. Traducción de Maquila Solidarity Network.

- Gearthard, J. (2001) La historia de la Responsabilidad Social de las empresas. Jornadas No. 7 año 2. CENTRA, San Salvador, 2001.

- Gereffi, Gary (1995) "Global Production systems and third world developement”. En Stallin Barbara, 
Global change, regional response, Cambridge University Press, Cambridge, 1995

- Gilly, Adolfo (2003) "Tiempo de escuchar”. La Jornada 2003 3/08/03. Disponible en: http://www.jornada.unam.mx/2003/ago03/030822/ $018 \mathrm{a} 1$ pol.php? printver $=1 \& \mathrm{fly}=2$, (consultado el 17 de febrero 2003).

- $\quad$ GMIES (2003 y 2004). Resumen de la maquila y libre comercio. Noviembre 2003. Observatorio de la Maquila y Libre Comercio. www.gmies.org.sv

- Intermon (2003). Comercio Justo 2003. Disponible en: (http://www. intermon.org/page.asp? id $=277$, consultado el 6/2/04)

- Mortimore, M. (2002) "When does apparel become a peril? On the nature of industrialization in the Caribbean Basin”. En Gereffi, G. Spener D and Bair, J. (Eds): "Free trade and uneven development. The North American Apparel Industry after NAFTA”. Temple University Press, Philadelphia, 2002

- OCDE (2000) Comercio internacional y estándares laborales básicos. Secretaría del Trabajo y Previsión Social (STPS), México DF, 2000

- OIT: (2003) Seventh Synthesis Report on the Working Conditions Situation in Cambodia's Garment Sector. Octubre de 2003. Disponible en:, (http://www. ilo.org/public/english/dialogue/ifpdial/ publ/cambodia7.htm). (Visitado el $10 \mathrm{de}$ febrero del 2004)

- O’ Rourke, D. (2000) “Monitoring the monitors: A critique of Pricewaterhouse Coopers (PWC) labor monitoring" http://nature.berkeley. edu/orourke/PDF/pwc.pdf

- $\quad$ O’ Rourke, D. (2003) “Outsourcing regulation: Analyzing Non-governmental Systems of Labor Standards and Monitoring". The policy Studies Journal. Volume 31, No 1. 2003.

- Oxfam Internacional (2002). Pobreza en tu taza. La verdad sobre el negocio del café. Disponible en: www. comercioconjusticia.com Visitada el 10 de febrero del 2004

- Peñaroya, M. (2004) Los ocho principios para conseguir el liderazgo de una marca http://www.noticias. com/index.php?action $=$ mostrar_artic ulo\&id $=57350 \&$ IDCanal $=1$

- Quinteros, C (2002). "Globalizando la acción social”. Realidad. UCA. San Salvador, No. 90, Noviembrediciembre 2002.

- Quinteros C (2005) "Corporate responsibility and the US-Central America Free Trade Agreement (CAFTA): are they compatible?" Development in practice, Vol. 15, Numbers 3 and 4. June, 2005.

- Quinteros C (2005) ¿Estamos soñando demasiado? Responsabilidad Social como respuesta para el 2005. GMIES, San Salvador, enero de 2005.

- $\quad$ Renard, M.C (1999) Los intersticios de la globalización: Un label (Max Havelaar) para los pequeños productores de café. Embajada Real de los Países Bajos, México DF, 1999.

- Rifkin, J. (2002) La era del acceso. La revolución de la nueva economía. Paidós Estado y Sociedad, Barcelona, 2000

- $\quad$ Ross Robert J.S y Chan, Anita (2002) "De Norte-Sur a Sur-Sur. La verdadera cara de la competencia global." Foreign Affairs. Septiembre - Octubre de 2002.

- Sojo, C. y Pérez Saínz, J.P. "Reinventar lo social en América Latina”, 
en Sojo (ed) "Desarrollo Social en América Latina”. FLACSO CR. San José, 2002

- Schmidheiny, S. (2004). Ponencia presentada en el Congreso ConvertiRSE. Cuidad de Guatemala, 3 y 4 de marzo, 2004.

- Vives, A. (2003) "Corporate Social Responsibility as a Tool for Competitiveness". Banco Interamericano de Desarrollo, 2003

\section{NOTAS}

1. Buena parte de las ideas de este artículo fueron expuestas en el artículo de la misma autora "¿Estamos soñando demasiado?” Publicado por GMIES en abril de 2005. Ver www. gmies.org.sv

2. Sólo en los EE.UU. existen tres iniciativas multisectoriales dedicadas a involucrar a más marcas en el mejoramiento de las condiciones de trabajo en las fábricas maquiladoras, a través del cumplimiento de códigos de conducta: La Fair Labor Association (FLA), que es la iniciativa más antigua, reúne al menos a 10 de las marcas más representativas de la cultura de consumo estadounidense (Liz Claiborne, Gap,
- WBG/ IFC (2003) "Race to the top: Attracting and enabling global sustainable business". Business survey report. Octubre de 2003.

- Werner K. y Weiss H. El libro negro de las marcas. El lado oscuro de las empresas globales. Editorial Suramericana, Buenos Aires, 2003.

Nike, etc.), la Social Accountability Internacional (SAI), que administra la SA 8000 que es una norma creada conjuntamente por organizaciones de derechos humanos, sindicatos y compañías (tales como Human Rights Watch, La Federación Internacional de Trabajadores de Textiles, Vestuario Calzado y Cuero, FITVCC y Avon) y que comprende un proceso de certificación de los proveedores de dichas empresas y el Worker Rights Consortium (WRC) que es una iniciativa orientada hacia las universidades estadounidenses y que fue desarrollada por las organizaciones de estudiantes activas en las protestas en contra de la explotación en las maquilas y la AFL CIO. 